\title{
O "abrasileiramento" das associações esportivas de Teutônia/ Estrela no Rio Grande do Sul
}

CDD. 20.ed. 796.08

\begin{tabular}{r|l} 
Cecília Elisa KILPP* & $\begin{array}{c}\text { *Departamento de } \\
\text { Educação Fisica, Uni- } \\
\text { versidade Federal do } \\
\text { Rio Grande do Sul. }\end{array}$ \\
\begin{tabular}{c|} 
Alice Beatriz ASSMANN \\
J anice Zarpellon MAZO*
\end{tabular} &
\end{tabular}

\section{Resumo}

As associações esportivas teuto-brasileiras de Teutônia/Estrela no Estado do Rio Grande do Sul sofreram o processo de abrasileiramento no período da Primeira Guerra Mundial (1914-1918) e da Segunda Grande Guerra (1939-1945). Este artigo objetivou identificar os conflitos de identidades culturais nas associações esportivas de Teutônia/Estrela desencadeados pelas ações nacionalizadoras conduzidas pelos interventores do Estado Rio Grande do Sul no período das grandes guerras mundiais. As fontes históricas consultadas revelaram que a prática de esportes tradicionais nas associações teuto-brasileiras enfraqueceu, como no caso do bolão, ao mesmo tempo que outros esportes foram incorporados, principalmente o futebol. A adesão a esta nova prática esportiva significa um movimento na direção do processo de integração às ações nacionalizadoras.

UnItermos: Esporte; Clubes; História.

\section{Introdução}

O presente estudo aborda o processo de abrasileiramento das associaçóes esportivas na cidade de Teutônia/Estrela, no Estado do Rio Grande do Sul, no período compreendido da Primeira Guerra Mundial (1914-1918) até o final da Segunda Guerra Mundial (1939-1945). O referido recorte temporal apóia-se no marco inicial da Primeira Guerra Mundial, onde a crise econômica mundial e o pangermanismo (a união dos países de origem germânica) ganham destaque, até o final da Segunda Guerra Mundial, quando a Alemanha é rendida e a perseguição aos quistos étnicos diminui. Nesta época, no cenário nacional, o Brasil é atravessado pelo Estado Novo (1937-1945), período no qual Getúlio Vargas e seu principal interventor no Estado, o general Oswaldo Cordeiro de Farias, fomentaram a campanha de nacionalização dos quistos étnicos, principalmente dos imigrantes alemães e seus descendentes, que no decorrer do texto serão citados como teuto-brasileiros. O recorte espacial, Teutônia/Estrela ${ }^{1}$, justifica-se por ser uma cidade onde são preservados os costumes alemães até os tempos atuais, especialmente nas associaçōes.

$\mathrm{O}$ associativismo esportivo engloba clubes, sociedades, agremiações, ligas, enfim, toda forma de organização esportiva. Nas associaçóes esportivas, os imigrantes alemães preservaram sua identidade étnica, por meio da manutenção de suas tradiçôes, seus costumes, sua língua materna e práticas culturais esportivas. Tais espaços são apontados (LANDO \& BARROS, 1980; MAZO, 2003; SILVA, 2006) como lugares para a prática do germanismo ${ }^{2}$, de sociabilidade e, ainda, de formação de lideranças e contatos comerciais.

As associaçõos eram vistas como espaços de reuniões sociais, culturais, políticas e econômicas. Neste sentido, considera-se que também exerceram o encargo da educação moral da elite urbana (média ou alta), detentora do capital econômico e cultural da sociedade (Ramos, 2000). Por isso, as associações são de grande importância para o estudo de uma sociedade, pois também são espaços de produção e afirmação de representaçōes culturais de identidades.

Além disso, as associações esportivas teutobrasileiras, por possuírem uma identidade étnica expressada pelo germanismo, foram alvo de açôes nacionalizadoras. A partir de 1938, com a nomeação do interventor Cordeiro de Farias, a perseguição aos quistos étnicos foi desencadeada intensamente. Diante deste contexto, as associaçõos esportivas 
teuto-brasileiras tiveram que presidir por novas regras e leis, gerando conflitos de identidades, pois desejavam manter os ideais fixados na sua cultura de origem da pátria mãe.

Diante do exposto, este estudo objetivou identificar os conflitos de identidades culturais nas associações esportivas de Teutônia/Estrela desencadeados pelas ações nacionalizadoras conduzidas pelos interventores do Estado Rio Grande do Sul no período das grandes guerras mundiais.

O caminho teórico-metodológico que orientou esta pesquisa foi na perspectiva da História Cultural (Burke, 2005; Pesavento, 2004), buscando-se entender as mudanças sócio-históricas nas associações esportivas frente às ações nacionalizadoras impostas no período demarcado para o estudo. Em busca de uma versão sobre o processo de abrasileiramento no âmbito do associativismo esportivo em uma cidade sul-rio-grandense distinguida, desde seu nome - Teutônia - pela identidade teuto-brasileira, neste estudo, optamos pela coleta e tratamento das fontes impressas. Estas foram garimpadas no Museu Henrique Uebel, de Teutônia, incluindo o arquivo documental e iconográfico. Além disso, consultamos livros editados e impressos por autores locais, estatutos das associações e edições comemorativas do aniversário de 50 e 75 anos da fundação da cidade de Estrela. Artigos, dissertações e teses foram utilizados na revisão bibliográfica.

A análise documental foi realizada de acordo com BACELlar (2005), em três etapas: levantamento e seleção de documentos, codificação dos dados que coincidem com a proposta da pesquisa e interpretação dos dados coletados. Nessa direção, foram construídas categorias de análise que privilegiaram as seguintes unidades de significado: práticas culturais e esportivas, representações de identidades étnicas e resistência das associações esportivas ao abrasileiramento. O resultado da análise documental é apresentado nas seções que seguem.

\section{Teutônia/ Estrela e o associativismo esportivo}

As práticas culturais de origem germânica foram trazidas pelos primeiros imigrantes alemães que chegaram a Teutônia/Estrela no final da década de 1850. Após estabelecerem a família e no trabalho, suas açôes voltaram-se à organização em comunidade, fundando, assim, as associações esportivas. Nessas associações os alemães preservaram seus costumes, seu germanismo e suas tradições por meio da produção de práticas e representaçōes culturais de identidade étnica teuto-brasileira. Em tais espaços não era permitida a filiação de pessoas de diferentes etnias, admitindo-se somente teuto-brasileiros. Esta situação favoreceu o distanciamento dos demais grupos étnicos que também imigraram para o Brasil.

De acordo com Oliveira (2007) a maior parte dos historiadores menciona o fato do isolamento geográfico e étnico das "colônias alemãs" como o principal fator de distanciamento e preservação de hábitos. Porém, é necessário ainda considerar a posição ocupada pelos imigrantes alemães perante a sociedade brasileira. A Constituição do Império, em 1830, opunha-se à concessão imediata de nacionalidade brasileira aos imigrantes alemães e seus descendentes; além disso, assegurava que a religião do país era a católica. Visto que os imigrantes alemães, em sua maioria, eram protestantes, tal escolha religiosa foi colocada como obstáculo (Roche, 1969).
Neste cenário, os imigrantes alemães não tinham direitos de cidadão definidos. Mesmo os descendentes nascidos no Brasil ou alemães naturalizados eram tratados como estrangeiros e tinham cidadania limitada, principalmente neste período inicial de sua instalação no país. Isto gerou certo isolamento social e até mesmo a marginalização do imigrante alemão, o que por outro lado favoreceu a preservação da cultura oriunda de sua terra natal.

Os imigrantes alemães, inicialmente, nem se percebiam como tais. Eram prussianos, austríacos, renanos, westfalianos, com língua e costumes diferentes. Mas a sociedade brasileira não distinguia este grupo heterogêneo. Assim, tiveram que se compreenderem como sendo alemães, e construir sua identidade étnica. Ao mesmo tempo, também, se constituíam como os "outros", os diferentes diante dos demais. A identidade teuto-brasileira passou a ser identificada como uma forma de não ser brasileiro (MAGALHÁEs, 1998).

Vale lembrar que os incentivos do governo para a vinda de imigrantes e mercenários abrangiam a possibilidade de aquisição da nacionalidade brasileira, ainda mais depois do apoio dos alemães ao governo brasileiro nas investidas que ocorreriam. A eminência de sucessivas batalhas, tanto por questóes políticas internas quanto para firmar a sua fronteira 
ante as invasões espanholas, convoca os imigrantes alemães a defenderem sua nova pátria logo após sua chegada no Brasil. Destacam-se os seguintes conflitos: Guerra Cisplatina (1825-1828); Guerra dos Farrapos (1835-1845); Guerra contra Rosas e Oribe (1851-1852); e Guerra do Paraguai (18641870) (Oliveira, 2007; Roche, 1969). No ano de 1840, houve batalhas também no território onde se constituiria mais tarde Teutônia/Estrela, território então pertencente à Taquari (Roche, 1969).

Após esta conjuntura de disputas, onde permanecia a fragilidade da demarcação política de fronteira e a expectativa por novas invasōes, foi criada a primeira associação esportiva de Teutônia/ Estrela, a "Kriegerverein" (Sociedade de Guerreiros) da Linha Clara no ano de 1874. Esta sociedade foi fundada por ex-combatentes alemães, conhecidos como "brummers", das guerras da Alemanha contra a Áustria e a Dinamarca que ocorreram antes destes emigrarem para o Rio Grande do Sul (KILPP, 2010). A "Kriegerverein" tinha como objetivo inicial preparar os imigrantes alemães para defenderem seus lares de incursões de espanhóis e de índios, além de animais perigosos, já que ocuparam regiōes de mata densa. Além da própria defesa, os associados também ajudaram a proteger a nova pátria, atuando junto às tropas brasileiras nas linhas de batalha.

Na Revolução Federalista de 1893, por exemplo, os membros da associação atiraram contra um acampamento de federalistas, defendendo a região de saques realizados pelas tropas (LANG, 2005; Roche, 1969). Durante este conflito, o centro da cidade de Teutônia/Estrela foi invadido pelas tropas revolucionárias, no dia 27 de maio de 1893. Depois de um combate com armas brancas com a Guarda Municipal, assumiram a Intendência. Com a aproximação das forças legalistas, o intendente fugiu e os revolucionários se retiraram. $\mathrm{O}$ sub-intendente Pércio Oliveira Freitas assumiu o cargo em 1894 e permaneceu até 1900 , tomando medidas severas para garantir a ordem pública diante de quaisquer acontecimentos revolucionários (DIEL, 1951, p.2).
No início do século XX, em 1910, a "Kriegerverein" mudou o nome para "Schützenverein" (Sociedade dos Atiradores) mantendo o idioma alemão (LANG, 1995). O germanismo era cultivado, especialmente, pelas associações de tiro ao alvo como também pelas sociedades de ginástica, como foi o caso da primeira sociedade de ginástica criada em Teutônia/Estrela, no ano de 1907. A "Turnverein Estrella" (Sociedade Ginástica Estrela), conhecida atualmente pela sigla SOGES era filiada a Liga de Ginástica do Rio Grande do Sul, que reunia associações de ginástica de várias regiōes do Estado (TESCHE, 1996).

O período em que apareceram as associações marca uma ascensão econômica dos comerciantes teutobrasileiros e a atuação dos "brummers" no incentivo ao germanismo, como acontecia na "Schützenverein". Nas associações, inicialmente, o idioma alemão constava em todos os registros e documentos, como também era falado no cotidiano e nas comemoraçôes de datas cívicas relacionadas à pátria de origem dos teuto-brasileiros (FLORES, 2004; SiLVA, 2006). Nas festividades prestavam homenagens a personalidades como Wilhelm II (último imperador alemão), o chanceler Otto von Bismarck (símbolo da unificação alemã) e Friedrich Ludwig Christoph Jahn, criador do Método Ginástico Alemão (Tesche, 1996). Apoiando-se em BurKe (2005) ponderamos que as festas e cerimônias em comemoração a datas cívicas alemãs cumpriam a função de afirmar a identidade dos teuto-brasileiros fortalecendo o sentimento de pertencimento a um grupo ao mesmo tempo em que buscavam diferenciar-se dos outros.

As associaçōes esportivas procuravam afirmar sua identidade étnica constantemente, o que despertou um olhar de desconfiança dos interventores do Estado. Diante de um cenário de construção e valorização da cultura nacional brasileira, desencadeia-se um forte movimento de nacionalização o qual repercutiu nas associações esportivas. Em Teutônia/Estrela percebeu-se o endurecimento das ações nacionalizadoras, que já davam sinais a partir da Primeira Guerra Mundial, no final da década 30.

\section{Marcas da nacionalização nas associações esportivas de Teutônia/ Estrela}

Até o início do século XX, o Brasil acolheu imigrantes de diversas etnias tendo em vista a intenção de "embranquecimento" da nação. Todavia, gradualmente sentiu-se a necessidade de construir uma identidade nacional. Nesse movimento, a identidade teuto-brasileira começa a ser problematizada, 
refletida e atualizada, não apenas pelo cultivo de suas tradiçōes, mas também pelo processo educativo através da escola e dos jornais na língua alemã (SILVA, 1997, p.50).

Todavia, os teuto-brasileiros não formavam um aglomerado de pessoas com concepções políticas idênticas. Para alguns, o envolvimento com sua origem, língua, costumes e condutas, extrapolava os limites do germanismo. Esta ideologia mais enraizada, chamada de pangermanismo e inspirada na Unificação Alemã, segundo GERTZ (1991, p.32), tomou proporçôes dificilmente definidas, porém é possível relacioná-la com o interesse da Alemanha pelos seus emigrantes a partir do último quarto do século XIX. Influenciados pela ideologia pangermanista, estimularam a endogamia e difundiram preceitos racistas, passando a ter problemas dentro do grupo e na sua relação com os outros.

Os conflitos acentuaram-se e os teuto-brasileiros tornaram-se alvo de tensōes, sendo considerados atores de conspirações e intrigas frente ao Estado (MAGALHĀES, 1998). Esta agitação já aparece antes mesmo do início da Primeira Guerra Mundial (1914-1918) gerando crises nas relações entre os teuto-brasileiros e o governo brasileiro. No ano de 1914 não havia mais imigração oficial, mesmo assim surgem outros problemas cívicos e culturais no Brasil (Roche, 1969).

Até o ano de 1917, o Brasil não possuía nenhuma lei de proibição do uso do idioma alemão e de manifestaçôes culturais. Porém, houve perseguições aos teuto-brasileiros e desde o início do século XX, o emprego do idioma alemão diminuiu nas sociedades recreativas do Rio Grande do Sul (Roche, 1969). A pretensão do governo de abrasileirar as comunidades com grande concentração de teutobrasileiros induziu a medidas como a proibição do idioma alemão nas escolas e associações, a troca compulsória do nome para a língua portuguesa e o registro obrigatório dos estatutos e atas na língua vernácula. Para estas ações, conforme Diel (1951), o governo contou com a colaboração da Liga de Defesa Nacional $(\mathrm{LDN})^{4}$. Outra medida também apoiada pela LDN foi a substituição das comemorações cívicas de heróis alemães por heróis e datas brasileiras, de forma a "contribuir para a formação da consciência nacional" (RAmOs, 2000, p.154).

Diante do crescimento da crise, algumas sociedades decidiram interromper suas atividades até o fim da guerra, ao invés de aceitar as condições do Estado para que permanecessem em funcionamento (SILVA, 1997). Enquanto que outras resistiram às imposições, pois não estavam dispostas a abandonar os costumes alemães, e mantiveram-se em funcionamento. Entretanto, aquelas que resistiram à pressão inicial, posteriormente foram forçadas a fazer algumas mudanças.

A cidade de Teutônia/Estrela não parecia estar nos planos do governo nas primeiras ações nacionalistas, sendo São Leopoldo o foco das medidas de abrasileiramento (RAmos, 2000). A Sociedade Ginástica Estrela, por exemplo, finalizou a construção do prédio sede em 1916 (HesSel, 1983) e não fechou durante o conflito; manteve o nome original - "Turnverein Estrella” -, porém passou a aceitar associados de outras etnias e realizar eventos em datas nacionais brasileiras como o Sete de Setembro e o Dia da Bandeira (Tотн \& Diniz, 1926, p.87-8). Outro caso foi o da "Schützenverein" Linha Clara que não fechou suas portas. Atualmente é denominada de Sociedade Cultural e Recreativa (SCR) da Linha Clara, mas não foram encontrados registros sobre a alteração de seu nome.

Ainda no mesmo período, as sociedades de Tiro ao Alvo, em razão do Decreto Lei no 3361 de 26 de outubro de 1917 foram incorporadas aos Tiros de Guerra. Os Tiros de Guerra visavam a formação e preparação militar de reservistas para o exército brasileiro, diferentemente das sociedades e clubes que tinham caráter esportivo e recreativo. Na região foram criados três Tiros de Guerra, sendo a "Schützenverein" de Linha Clara incorporada pelo Tiro de Guerra de Teutônia, no 648, criado no ano de 1920 (Tотн \& Diniz, 1926, p.124).

Após a Primeira Guerra Mundial, as sociedades de ginástica cresceram significativamente no Rio Grande do Sul (Tesche, 1996). Estas sociedades começaram a programar novamente eventos comemorativos, competiçōes e festividades, onde se exaltava a cultura alemã com comemorações de datas importantes da terra natal. Em Teutônia/Estrela, não foi diferente, e a prática que mais cresceu foi o bolão 5 . Segundo Schierholt (2002), o primeiro clube fundado na região foi o Club Unicum no ano de 1921. Além deste, vários outros grupos já realizavam a prática em casas comerciais, como forma de lazer desde o final do século XIX. A SCR da Linha Clara e a SOGES possuíam local apropriado para a prática por interesse de seus associados. Porém, a finalidade recreativa do bolão adiou a institucionalização de grupos nestas sociedades.

A prática do bolão não foi alvo das autoridades ou pelo menos não há registros na região. No entanto, os encontros para jogar boláo também se configuravam em reuniōes voltadas à discussão de diversos assuntos de ordem política, econômica e social, sendo que o idioma corrente era o alemão. Talvez não tenha despertado a 
desconfiança das autoridades por ser visto como uma prática de lazer, e por possuir poucas sedes fixas sendo jogado muitas vezes junto às casas comerciais.

$\mathrm{Na}$ década seguinte, anos 30 , a prática do bolão continuou conquistando novos adeptos. Porém, iniciaram-se as perseguições raciais nazi-fascistas na Europa Ocidental, levando para além desses limites o nacionalismo ferrenho. Estes acontecimentos chegariam ao Rio Grande do Sul e repercutiriam nos quistos étnicos, como também no associativismo esportivo. As práticas esportivas tradicionais não seriam mais as mesmas; o bolão, o tiro ao alvo e a ginástica seriam ressignificados, mas conservandose elementos da cultura alemã, como também novos esportes seriam incorporados vislumbrando a construção de uma cultura brasileira.

\section{O conflito de identidades nas associações esportivas de Teutônia/ Estrela}

A década de 30 no Brasil foi uma época de acentuação do preconceito racial e religioso e novamente o país sofreu pressão nas fronteiras. $\mathrm{O}$ governo buscava a unidade e a homogeneização cultural dos grupos étnicos do país, evitando a consolidação de uma ideologia de multiculturalismo (WAINBERG, 1996). Com a publicação dos decretos de 12 de dezembro de 1930 e 7 de janeiro de 1932, o governo proibiu a imigração e o nacionalismo brasileiro ganhou força (Pilatti, 2006; Roche, 1969).

As Constituições promulgadas em 1934 e 1937 ainda estabeleceram quotas para a entrada de estrangeiros, preservando assim a estrutura racial e cultural do Brasil (Roche, 1969). No entanto, o Decreto-Lei no 383 de 18 de abril de 1938, além de estabelecer uma imigração dirigida, proibiu estrangeiros residentes no Brasil de exercerem atividades políticas. As autoridades julgavam que as associações também eram locais onde os teuto-brasileiros discutiam assuntos políticos. Portanto, o Decreto-Lei representou uma forma de controle, permitindo a organização de associações somente para fins beneficentes ou de assistência e sem a possibilidade de receber auxílio de outro país. Ainda, foi proibido o uso de bandeiras, uniformes e distintivos de outros países, organização de desfiles, manutenção de jornais e revistas (Pilatti, 2006). Apesar disso, foi o período de maior vislumbre do pangermanismo e o nazismo destituiu o caráter utópico desta cultura.

Neste período conturbado e vigiado, houve o fechamento de algumas associaçōes, enquanto outras mantiveram suas atividades denotando um enfrentamento do abrasileiramento forçado. Aquelas que continuaram com suas atividades mudaram o nome, receberam associados de outras etnias, mantiveram seus encontros e festejos, mas mudaram algumas características como, por exemplo, evitando falar em idioma alemão publicamente. Foram construídas diferentes estratégias de resistência pelos teuto-brasileiros (GERTZ, 1980).

As associações aumentaram a gama de práticas esportivas oferecidas para além daquelas identificadas com os teuto-brasileiros. A década de 30 foi o período de maior expressão dos esportes coletivos no Estado, também na região do Vale do Taquari, onde está localizada Teutônia/Estrela. As sociedades de ginástica incluíram vários esportes anglo-saxōes como o basquetebol, o voleibol e o futebol.

A SOGES constituiu sua equipe de basquetebol visando a prática recreativa, mas, posteriormente, tomou parte de competições amadoras (SCHIERHOLT, 2002, p. 333). O voleibol também foi incorporado pela SOGES, mas não havia um local adequado para a prática deste esporte. $O$ ginásio foi construído em 1935, no mesmo ano da inauguração do campo para a prática do futebol. A própria ginástica, uma prática tradicional, conquistou espaço para treinamento na SOGES apenas dois anos antes do voleibol.

A SOGES se manteve em funcionamento neste período, provavelmente, por ampliar a oferta de esportes coletivos, os quais inicialmente eram pouco associados com os teuto-brasileiros. Também, porque a SOGES passou a aceitar membros de origem étnica diferente dos alemães, mudou o idioma regente para o português e passou a realizar comemorações de datas cívicas brasileiras. Mas apesar destas mudanças o nome continuava em alemão - "Turnverein Estrella" - e manteve-se até 16 de junho de 1945. Em virtude da fusão com a Sociedade dos Intrometidos, passou a chamar Clube Comercial Estrela. Somente em 1950 foi adotada a denominação atual (Art. 1º do Estatuto da Sociedade Ginástica Estrela de 19 de outubro de 2006 - Estrela, 2006).

Embora a SOGES tivesse um campo de futebol, este esporte era praticado de maneira pouco expressiva no período. Os primeiros clubes fundados 
foram o Grêmio Esportivo Estrelense e o Sport Club Oriental em 1921 (SCHIERHOLt, 2002, p.319). Posteriormente foram organizadas associações para a prática do futebol por empresas, grupos ou bairros nas cidades de Teutônia/Estrela, como o Estrela Futebol Clube e o Grêmio Esportivo e Recreativo Canabarrense fundados em 1931 (Diel, 1951, p.16).

$\mathrm{Na}$ segunda metade da década de 30 , foi fundada a Liga de Futebol do Alto Taquari, envolvendo os municípios de Teutônia/Estrela, Corvo, Roca Sales, Muçum, Encantado, Arroio do Meio e Lajeado (Hessel, 1983). Os clubes de futebol ganharam força em Teutônia/Estrela, sendo organizados três no princípio da década de 40, representando os bairros desenvolvidos na época, Teutônia, Boa Vista e Westfália (antiga Vila Schmidt): Sociedade Esportiva e Recreativa Gaúcho, Boa Vista Futebol Clube e Sociedade Esportiva Flamengo. Tais clubes também integravam a Liga de Futebol, que congregou associações de municípios compostos por diferentes etnias, o que favoreceu para que o futebol se constituísse em um esporte nacional.

Nos clubes houve uma recomposição da identidade cultural dos teuto-brasileiros. Juntamente com os torneios de futebol de final de semana, realizavam suas festas, reuniōes, cantorias e germanidade. Assim, os teuto-brasileiros preservaram seus costumes ao cultivarem a brasilidade junto com a germanidade atravessadamente por meio do esporte de maneira que não fosse completamente visível aos olhos do interventor (KILPp, 2010).

No período de 1938 a 1943, foi nomeado interventor do Estado o coronel Oswaldo Cordeiro de Farias, cujo foco central de sua política nacionalizadora incidiu no combate aos "quistos étnicos" (Gertz, 2005, p.34). Curiosamente, Cordeiro de Farias deslocou-se da capital até Teutônia/Estrela em 1939, quando era inaugurada uma Usina termoelétrica. No ano seguinte, interferiu na administração municipal nomeando para o lugar de Edmundo Alfredo Steyer, Sabino Menna Barreto. Logo após, em 1941, fez nova intervenção, delegando a função de governo do município à Cláudio de Toledo Mercio (Diel, 1951, p.3).

Já no primeiro ano em que assumiu a função de interventor, percebe-se que Cordeiro de Farias foi atuante em vários campos, inclusive no associativismo. As ações nacionalizadoras repercutiram em intensa depredação e saques das associações esportivas teuto-brasileiras. As sociedades de Tiro ao Alvo foram especialmente atingidas, pois possuíam armas e atiradores treinados, e em razão disso algumas decidiram fechar suas portas. A SCR da Linha Clara cessou suas atividades em 1938, quando foram forçados a desativar seus estandes de tiro, bem como eliminar todo o arquivo histórico e documental da entidade, que era escrito em língua alemã (Magedanz, 2004). Estes fatos explicam a ausência de registros das práticas e atividades promovidas pela sociedade até o ano de seu retorno. Além do acervo, as armas também foram confiscadas. Alguns itens foram salvos, como, por exemplo, um dos primeiros alvos, datado de 1910, que foi enterrado pelos antigos sócios e encontra-se atualmente na sede da sociedade (KILPP, 2008).

Outra ação decisiva para as associações esportivas foi a criação do Decreto Lei no 3199 de 1941, o qual convocava todas as sociedades a licenciarem-se perante o controle organizacional do Estado, antes caracterizado pela livre associação. Esta medida levou a LDN e as autoridades policiais a uma cassação com depredações, saques e queima de acervos de associaçōes teuto-brasileiras não licenciadas e inadimplentes. As sociedades eram portadoras de uma cultura que não se manifestava apenas na prática da ginástica, do tiro e do bolão, mas também, e principalmente, no idioma falado nas reuniōes de diretoria, na redação das atas e estatutos dos clubes, nas canções entoadas, nas comemorações e competições, entre outras manifestaçôes. Por isso, estes centros de encontro tornavam-se espaços políticos dos teuto-brasileiros, o que ameaçava o nacionalismo reverenciado por Getúlio Vargas na época do Estado Novo.

No ano de 1945 houve a queda do presidente Getúlio Vargas e com o fim do período ditatorial, algumas das associações esportivas que tinham sido assoladas pelas açōes nacionalizadoras, retomaram gradualmente suas atividades. Foi assim com a SCR de Linha Clara que em 18 de janeiro de 1953 foi reativada, após uma reunião com 55 dos antigos sócios da sociedade. Em seguida foi doada uma área de terra para a construção do estande de tiro ao alvo e assim retomada a competição do Tiro-Rei, que permanece até os dias atuais, sem interrupções (Magedanz, 2004). 


\section{Considerações finais}

O associativismo esportivo em Teutônia/Estrela foi iniciativa dos imigrantes alemães que se instalaram na região. Nos primórdios, os esportes oferecidos pelas associações eram o tiro ao alvo, o bolão e a ginástica. Para além das práticas, as associações eram espaços, onde ocorriam reuniōes para discutir atividades sociais, como também questões políticas e econômicas relacionadas aos teuto-brasileiros. Nas associações e por meio delas, os teuto-brasileiros preservaram sua identidade étnica exaltando o germanismo e disseminando suas tradições, costumes, língua materna e práticas esportivas.

As associações sul-rio-grandenses distinguidas pela identidade étnica teuto-brasileira foram alvo de forte opressão no período da Primeira Guerra Mundial, quando ocorreu a unificação do Estado alemão. Porém, as ações nacionalizadoras deste período não atingiram profundamente a "Turverein Estrella", que se manteve em funcionamento e sustentou o nome original. Todavia, consentiu mudança no seu estatuto com a finalidade de permitir o ingresso de associados identificados com outros grupos étnicos a partir de 1919.

Da mesma forma que a sociedade de ginástica, a "Schützenverein" foi abarcada pelo processo de nacionalização, mas de forma menos intensa até o final da Primeira Guerra Mundial. A sociedade de atiradores prosseguiu com suas atividades sociais e práticas esportivas. Porém, em 1920, por força da legislação brasileira que criou os Tiros de Guerra, foi incorporada ao Tiro de Guerra de Teutônia, número 648.

No caso das associações de Bolão, não foram encontrados registros de ações de abrasileiramento no período. Talvez porque a maioria dos grupos de praticantes não era institucionalizado e não possuía sede fixa. Mas, a prática do bolão reunia um bom número de pessoas e mantinha costumes de sua origem.

O Estado Novo representa o período ditatorial que radicalizou ainda mais as açōes sobre as associações teuto-brasileiras. Com a aprovação do Decreto Lei n. 3.199 de 1941, as associações teuto-brasileiras foram obrigadas a se habilitarem ao controle organizacional do Estado. Nesse cenário de conflito identitário, algumas associações sofreram com depredaçōes, saques, queima de acervos e até mesmo cassação. A SRC de Linha Clara, por exemplo, foi hostilizada e teve seu arquivo queimado, desencadeando sua desativação por 15 anos, de 1938 a 1953. Mas alguns sócios da SRC de Linha Clara encontraram formas de preservar a memória quando enterraram um dos primeiros alvos da associação, datado de 1910, para evitar que fosse achado e extinguido pelas forças nacionalistas.

Foi um período difícil para o associativismo teuto-brasileiro, no qual coexistiam ações de abrasileiramento e estratégias de aversão a tal imposição. Nessa conjuntura emerge a reconfiguração da identidade étnica dos teuto-brasileiros. As associações desempenharam um papel fundamental neste processo de perpetuação das práticas esportivas e de produção de outras representaçôes culturais.

A incorporação de esportes coletivos de origem anglo-saxônica abalou a cultura esportiva das associações, que tradicionalmente ofereciam esportes identificados com os teuto-brasileiros. Contudo, a chegada do futebol e a organização de associações de futebolistas não significou uma ruptura com as antigas práticas esportivas, pois estas permaneceram. Assim como as disputas de tiro ao alvo, bolão e ginástica, os torneios de futebol se constituíram em uma forma de difundir o germanismo, porém agregando novos elementos culturais.

Com o fim do Estado Novo e da Segunda Guerra Mundial, em 1945, percebe-se que as associaçōes teutobrasileiras tinham aderido a novos esportes. A SOGES, por exemplo, além do futebol, introduziu a prática do basquetebol e voleibol. Estas mudanças, provavelmente, revelam a integração das associações teuto-brasileiras ao processo de abrasileiramento. Contudo, ao mesmo tempo, a sociedade de ginástica, as associações de atiradores e os grupos de bolão foram renovados.

\section{Notas}

1. No período demarcado neste estudo, a cidade de Teutônia ainda fazia parte de Estrela, uma cidade referência na região e com expressiva presença de teuto-brasileiros. No início da década de 80, Teutônia se desmembrou de Estrela pela Lei 7.542 de 5 de outubro de 1981 (Тотн \& Diniz, 1926).

2. A palavra germanismo, do alemão "deutschtum", se refere ao modo de ser alemão, à ideologia difundida entre os teuto-brasileiros, destinada a preservar sua identidade étnica, sua cultura, sua língua, a lealdade ao país de origem (GERTZ, 1980, p.207). 
3. São os mercenários contratados pelo governo. O nome refere-se a "resmungão", pois reclamavam que seu saldo foi pago com moedas de cobre e não ouro ou prata, como prometido (OliveIRA, 1987).

4. A LDN foi criada no ano de 1916, no Rio de Janeiro, e um núcleo foi instalado no Rio Grande do Sul em 1937, ocupando o cargo de presidente do Diretório Regional o interventor do Estado, general Osvaldo Cordeiro de Farias. Tinha a finalidade principal de incentivar o civismo e patriotismo no país. Por iniciativa da LDN, a Semana da Pátria passou a vigorar e o ensino da língua portuguesa passou a ser obrigatório nas colônias de imigrantes. Junto com o Departamento de Imprensa e Propaganda (DIP) realizavam caravanas nacionalistas e difundiam comemorações de datas cívicas com exaltadas demonstrações de brasilidade (MAzo, 2003).

5. O bolão era praticado em clubes na Alemanha desde 1768. Este esporte originou o boliche, com algumas diferenças: a bola do bolão pesa 10 ou $11 \mathrm{~kg}$ e no número de pinos é nove. Também há pequenas diferenças na pista de rolamento. O jogo de bolão consiste em derrubar o maior número de pinos jogando cinco bolas (www.kegelsport.com.br).

A autora Cecília Elisa Kilpp é bolsista CAPES.

\begin{abstract}
The "abrasileiramento" of the sports associations from Teutônia/Estrela in Rio Grande do Sul

The German-Brazilian sport associations of Teutônia/Estrela in the State of Rio Grande do Sul suffered the process of abrasileiramento in the period of the World War I (1914-1918) and of the World War II (1939-1945). This article aimed to identify the conflicts of cultural identities in the sport associations of Teutônia/Estrela developed by the nationalization actions leaded by the intervenors of the Rio Grande do Sul State in the period of the great world wars. Historical sources revealed that the practice of traditional sports in the German-Brazilian sport associations weakened, asthe bolão, while other sports were incorporated, mainly the soccer. The adhesion to this new sport means a movement in the direction of the process of integration in the nationalization actions.
\end{abstract}

UnITERMS: Sport; Club; History.

\title{
Referências
}

BACELLAR, C. Fontes documentais: uso e mau uso dos arquivos. In: PINSKI, C. (Org.). Fontes históricas. São Paulo: Contexto, 2005. p.23-80.

BURKE, P. O que é história cultural? Rio de Janeiro: Jorge Zahar, 2005.

DIEL, A. Revista Jubileu Diamante Estrela. Estrela: Manufatora Estrelense, 1951. (Livro comemorativo dos 75 anos do Município de Estrela).

ESTRELA. Estatuto da Sociedade Ginástica Estrela, de 19 de outubro de 2006. Discrimina a fundação da Sociedade Ginástica Estrela, mudança de denominação e nome atual. Estrela, 19 out. 2006. Art 1º, p.1.

FLORES, H. História da imigração alemã no Rio Grande do Sul. Porto Alegre: EST, 2004.

GERTZ, R. O Estado Novo no Rio Grande do Sul. Passo Fundo: UPF, 2005.

O integralismo na zona colonial alemã. In: LANDO, A.M.; BARROS, E.C. Rio Grande do Sul: imigração \& colonização. Porto Alegre: Mercado Aberto, 1980. p.207-33.

O perigo alemão. Porto Alegre: UFRGS, 1991.

HESSEL, L. Município de Estrela. Porto Alegre: UFRGS, 1983.

KILPP, C.; MAZO, J.Z.; LYRA, V.B. Um olhar histórico sobre a emergência dos primeiros clubes esportivos na cidade de Teutônia, no Rio Grande do Sul. Pensar a Prática, Goiânia, v.13, n.1, p.1-16, 2010.

Kriegerverein: a constituição da Sociedade de Guerreiros e das primeiras associações esportivas de Teutônia/ Estrela (1874-1950). Trabalho de Conclusão de Curso (Licenciatura em Educação Física) - Curso de Educação Física, Universidade Federal do Rio Grande do Sul, Porto Alegre, 2008.

84 • Rev. bras. Educ. Fís. Esporte, São Paulo, v.26, n.1, p.77-85, jan./mar. 2012 
LANDO, A.; BARROS, E. Capitalismo e colonização: os alemães no RS. In: LANDO, A.; BARROS, E. (Orgs). Rio Grande do Sul: imigração \& colonização. Porto Alegre: Mercado Aberto, 1980. p.12-39.

LANG, G. As sombras do passado. Campo Bom: Ipanema, 2005.

Colônia Teutônia: história e crônica (1898-1908). Novo Hamburgo: Gráfica Sinodal, 1995.

MAGALHÃES, M. Pangermanismo e nazismo: a trajetória alemã rumo ao Brasil. Campinas: UNICAMP, 1998.

MAGEDANZ, A. Linha Clara, Teutônia e os $\mathbf{1 8 0}$ anos da imigração alemã no RS. Teutônia: o autor, 2004.

MAZO, J. A emergência e a expansão do associativismo desportivo em Porto Alegre (1867-1945): espaço de representação da identidade cultural brasileira. Tese (Doutorado em Ciências do Desporto) - Universidade do Porto, Porto, 2003. OLIVEIRA, P. A imigração alemã e a introdução do Punhobol no RS. Dissertação (Mestrado em Ciência do Movimento) - Centro de Educação Física e Desportos, Universidade Federal de Santa Maria, Santa Maria, 1987.

OLIVEIRA, R. Etnicidade e poder: a construção da cidadania entre os colonos de origem alemã e seus descendentes no Rio Grande do Sul (1824-1889). In: SIMPÓSIO NACIONAL DE HISTÓRIA, 24., 2007, São Leopoldo. Anais... São Leopoldo: UNISINOS, 2007.

PESAVENTO, S. História \& história cultural. 2. ed. Belo Horizonte: Autêntica, 2004.

PILATTI, L. O efeito de trava de um habitus: anotaçóes sobre o papel da Lei da Nacionalização no esvaecer do habitus esportivo do imigrante alemão no estado do Paraná. In: PILATTI, L.; GEBARA, A. (Orgs.). Ensaios sobre história e sociologia nos esportes. Jundiaí: Fontoura, 2006.

RAMOS, E. O teatro da sociabilidade: os clubes sociais como espaço de representação das elites urbanas alemãs e teuto-brasileiras - São Leopoldo 1858-1930. Tese (Doutorado em História) - Universidade Federal do Rio Grande do Sul, Porto Alegre, 2000.

ROCHE, J. A colonização alemã e o Rio Grande do Sul. Porto Alegre: Globo, 1969.

SCHIERHOLT, J. Estrela: ontem e hoje. 2. ed. Lajeado: O autor, 2002.

SILVA, H. Sogipa: uma trajetória de 130 anos. Porto Alegre: Gráfica Editora Palloti, 1997. (Publicação comemorativa).

Entre o amor ao Brasil e ao modo de ser alemão. São Leopoldo: Oikos, 2006.

TESCHE, L. A prática do Turnen entre imigrantes alemães e seus descendentes no RS: 1867-1942. Ijuí: UNIJUÍ, 1996. TOTH, E.; DINIZ, A.G. Álbum commemorativo do cincoentenário do Município de Estrella. Estrela: Prefeitura de Estrela, 1926.

WAINBERG, J.A. Políticas de imigração: o preconceito racial e homogeneização cultural. Revista Porto \& Vírgula, Porto Alegre, n.26, p.39-53, 1996

$$
\begin{array}{r}
\text { ENDEREÇO } \\
\text { Cecília Elisa Kilpp }
\end{array}
$$$$
\text { R. Eng. Antônio Carlos Tibiriça, 440/ } 102
$$$$
\text { 90690-040 - Porto Alegre - RS - BRASIL }
$$$$
\text { e-mail: cecilkilpp@yahoo.com.br }
$$

Recebido para publicação: 12/ 04/ 2011

Revisado: 21/ 10/2011

Aceito: 26/ 10/ 2011 